\title{
A etiologia do sintoma psicossomático: sua relação com a reincidência traumática e o retraimento autista
}

\author{
Etiology of psychosomatic symptoms: its relationship with traumatic recurrence \\ and autistic withdrawal
}

\author{
Sebastião Abrão Salim* \\ * Professor adjunto R4, Faculdade de Medicina, Universidade Federal de Minas Gerais (FMUFMG), Belo Horizonte, MG. Psicanalista didata, \\ Sociedade Psicanalítica do Rio de Janeiro (SPRJ) e Núcleo de Belo Horizonte.
}

\section{Resumo}

A etiologia do sintoma psicossomático continua indefinida, apesar de inúmeros estudos de ciências afins. Apresento a hipótese de que este só se desenvolve em paciente portador de personalidade autista como predisposição, isto é, que tenha barreiras autistas apego às "formas autistas" e aos "objetos autistas" - em resposta a um trauma no período fetal ou do nascimento, que promova sensação de descontinuidade física. Essas formas e objetos são elementos do próprio corpo, como a saliva, a língua, os dedos e as mãos em contato com suas próprias superfícies sensórias, mais a pele. A soma do registro dessas sensações pela memória implícita incipiente ou em desenvolvimento funciona como um ego biológico sem sujeito cognitivamente interpretante. O paciente portador de personalidade autista, diante de um novo trauma com a mesma sensação de morte, retira-se para o estado de homeostase autista, como se já soubesse o caminho, e aí fica hospedado. Dessa forma, seu corpo se converte em uma "mãe suficientemente boa", conforme conceituada por Winnicott. O sintoma psicossomático é uma representação das defesas biológicas e não um representante de conflitos que têm como base elementos sexuais ou destrutivos reprimidos. Inclui a angústia de morte, de deixar de existir. Os fenômenos psicossomáticos escondem, paradoxalmente, uma luta pela vida e, especialmente, pela sobrevivência psíquica do paciente, segundo MacDougall.

Descritores: Sintoma psicossomático, personalidade autista, trauma, percepção sensória.

\begin{abstract}
Etiology of psychosomatic symptoms remains unclear, in spite of many studies by similar sciences. I present the hypothesis that the patient needs to have an autistic personality as predisposition, i.e., he needs to have autistic barriers - attachment to "autistic forms" and to "autistic objects" - in response to a fetal or postpartum trauma that produces a feeling of physical discontinuity. These forms and objects are elements of the body itself, such as saliva, fingers, tongue, and hands in contact with its own sensory surfaces, especially the skin. The sum of these registers by incipient or developing implicit memory works as a biological ego without a cognitively interpreting subject. The patient with an autistic personality withdraws to the autistic homeostatic state when there is a trauma with an instinctive notion of death, as if he already knew the way and remains in suspension there. Thus, the body becomes a "good enough mother," as quoted by Winnicott. Psychosomatic symptoms are a representation of biological defenses, and not a representative of conflicts based on repressed sexual or destructive elements. It includes death anxiety, of no longer existing. Psychosomatic symptoms paradoxically hide a fight to live and especially to the patient's psychic survival, according to MacDougall. Keywords: Psychosomatic symptom, autistic personality, trauma, sensory perception.
\end{abstract}




\section{Introdução}

O sintoma psicossomático (SP) permanece sem explicação etiológica, apesar das inúmeras pesquisas originárias de distintas áreas do conhecimento biológico e psicológico. $\mathrm{O}$ autor deste trabalho tem como objetivo apresentar a hipótese de que a etiologia do SP tem relação com a reincidência traumática e o retraimento autista. Ambos são respostas biológicas instintivas para o apaziguamento e o prolongamento da vida.

Utiliza, para sua formulação, seus conhecimentos psicanalíticos e seus estudos sobre o trauma de acordo com o Manual de Diagnóstico e Estatística das Perturbações Mentais (DSM-IV), o retraimento autista, a percepção sensória, a memória implícita e o estresse.

\section{Revisão da teoria psicanalítica do sintoma psicossomático}

A descoberta de Freud ${ }^{1}$ da vida inconsciente e sua relação com a psicopatologia da neurose, a formação do sonho e o fenômeno de transferência presente na relação analista/analisando estenderam-se, de forma gratuita, à etiologia do SP, como se o mesmo fosse também um representante simbólico de conteúdo sexual reprimido.

$\mathrm{Na}$ esteira da correção desse extremismo, Ferenczi ${ }^{2}$ cunhou a expressão "organo-neurose" para diferenciar as entidades psicossomáticas da neurose histérica.

Mais tarde, Cannon ${ }^{3}$ demonstrou que estados emocionais vinculados a sentimentos reprimidos, como o ódio, a culpa, a reprovação, a dependência, a inveja e outros, tinham concomitantes fisiológicos específicos, dependendo de cada um desses sentimentos.

Pouco depois, a escola de Alexander ${ }^{4}$ tornou-se marco nessa evolução. Para ele, o SP "seria uma resposta fisiológica ao estado de tensão emocional crônica, mantida por processos inconscientes presididos pelo sistema nervoso autônomo; não eram representantes simbólicos de conteúdo inconsciente sexual reprimido".

Como ilustração, a úlcera duodenal era resultante da antítese entre as tendências para a regressão e a necessidade de superá-la. Decorria da hiperatividade fisiológica determinada por aquele sistema. As vias parassimpáticas eram relacionadas com a dependência, e as vias simpáticas, com as tendências de luta e competição. Seus estudos levaram-no a concluir que os transtornos psicofisiológicos constituíam respostas padrão a determinadas situações de conflito dentro do sujeito. Daí desenvolveu a "teoria da especificidade dos conflitos".

Nessa mesma linha, Dunbar ${ }^{5}$ sustentou a hipótese de que "cada doença teria um perfil psicológico próprio determinado por experiências infantis traumáticas". Descreveu a "personalidade traumatofílica, isto é, seu portador repete em sua vida situações traumáticas acontecidas sem consciência desse fato". Como será salientado adiante, essa relação com o trauma tem a ver com o esboço teórico apresentado pelo autor para propor sua teoria sobre a etiologia do SP e a teoria da fragilidade do órgão.

Os estudos desses três últimos autores aproximaram a etiologia desse sintoma ao sistema nervoso autônomo. Infelizmente, os analistas, a partir da metade do século XX, foram desvinculando a psicanálise da biologia $\left(\mathrm{Kande}^{6}\right)$ em troca da valorização das teorias das relações objetais e da intersubjetividade. O próprio Freud fez o mesmo, quando, no início de seus estudos, abandonou seu Projeto para uma psicologia cientifica ${ }^{7}$ e, depois, seu trabalho Além do princípio do prazer $^{8}$, ambos tentativas de encontrar as bases biológicas para os processos mentais. Abandonou-os, mas não deixou de vaticinar, até o fim de sua obra, que no futuro essas bases haveriam de ser encontradas.

Com exceção de Winnicott ${ }^{9}$, talvez pela sua proximidade com a pediatria, e de Tustin $^{10}$, com seus estudos sobre a experiência física sensória, os psicanalistas têm recaído no entendimento do SP como "uma linguagem corporal" para expressar conflitos reprimidos, isto é, um auxiliar para a expressão verbal limitada nesses pacientes. Desconhecem, assim, que o universo psicossomático é um universo sem palavras e sem símbolos.

Entre os psicanalistas atuais, McDougall ${ }^{11}$, embora de acordo com essa conceituação biológica, mostra-se indefinida, por vezes interpretando o SP como "regressão a um erotismo infantil inicial". Cita-se, ainda, Marty \& M'Uzan ${ }^{12}$, com o conceito de "pensamento operatório". Descrevem o SP como concomitante fisiológico, sem abandonar de todo o vértice simbólico. Essa questão continua reincidente.

Para o autor, existe sempre a angústia de morte ou de loucura nesse paciente, afirmação abonada por McDougall"1 , que assim se expressa: "Os fenômenos psicossomáticos escondem, paradoxalmente, uma luta pela vida, e especialmente pela sobrevivência psíquica do ser".

\section{A percepção sensória e a memória implícita}

A percepção sensória tem significado marcante desde a vida fetal. Embora Winnicott ${ }^{13}$ não estendesse seus estudos ao período fetal do desenvolvimento psíquico, deixou clara sua importância nos seus 
trabalhos. Afirmou que: "A base da psique é o soma, e, em termos de evolução, o soma foi o primeiro a chegar. A psique começa como uma elaboração imaginativa das funções somáticas (...) A elaboração imaginativa da função deve ser considerada existente em todos os níveis de proximidade do funcionamento físico propriamente dito (...) refere-se à fantasia quase-física, àquela que está menos ao alcance da consciência”.

Tustin $^{10}$, com seus estudos sobre o autismo psicogênico e o que chamou de "barreiras autistas em pacientes psiconeuróticos", aproximou-se dessa abordagem do psiquismo fetal. Embora não a explicitasse ou a sistematizasse, explicitou a importância da geração auto-sensória pelo feto, como discriminado em recente artigo do autor ${ }^{14}$.

Posteriormente, Ogden ${ }^{15}$ desenvolveu o conceito de uma posição autista-contígua, anterior à posição esquizoparanóide, deixando implícita sua continuidade desde a vida fetal. Segundo ele, a matriz psíquica dessa posição gera a psicopatologia psicótica, como ilustrou com casos clínicos.

Para o autor, essas contribuições e outras da neurobiologia validam a possibilidade de a percepção sensória constituir nossa primeira representação psíquica com registro pela incipiente memória implícita fetal. A percepção sensória não é uma presença inerte. Responde pela noção subjetiva do existir do feto e do recém-nascido, de quem sou e onde estou. A memória implícita tem sede na amígdala cerebral. Sua função básica é a regulamentação dos elementos e dos procedimentos responsáveis pela preservação da sobrevivência. Daí ser designada também como memória de procedimento ou de longo prazo. Funciona independente da consciência, a exemplo do inconsciente freudiano.

Talvez essa memória tenha relação com o conceito de Freud ${ }^{16}$ de "ego corporal", conceito que ele não desenvolveu. Apenas mencionou que: "O ego é antes de tudo corporal". Em nota de rodapé, acrescentada em 1927, continua ele: "Isto é, o ego em última análise deriva das sensações corporais, principalmente das que se originam da superfície do corpo (a pele - meu)". Poder-se-ia dizer que o ego, nesse período inicial, é um ego biológico formado pelo registro contínuo dessas percepções sensórias pela memória implícita, cujo rudimento existe desde a fecundação.

A maturação do sistema nervoso central do feto, ditada pela embriologia, nesse período, não o torna hábil para capacidades cognitivas. A aquisição destas começa após os primeiros 10 dias de vida pós-natal, segundo Harlow $^{17}$ e Levine ${ }^{18}$, com suas experiências em macacos e ratos recém-nascidos. Segundo esses autores, há diferença de comportamento desses animais se separados das matrizes logo após o nascimento ou se separados depois de 10 dias do nascimento. No primeiro caso, quando ambos são colocados em contato com as matrizes, após 6 meses de separação, mostram-se estranhos, procuram o isolamento e estão desvitalizados. Esse estado é irreversível e pode ser observado, tempos depois, com os dois tipos de animais. O mesmo não ocorre com o segundo grupo. Logo se socializam e recuperam sua vitalidade. São experiências que mostram os resultados do trauma e a existência de duas matrizes psíquicas, diferenciação importante para a psicopatologia. Pode-se afirmar que há uma matriz autista presidida pelo ego biológico e outra quando o recém nascido adquire um ego psíquico com capacidade para distinguir entre o eu e o não-eu, entre sujeito e objeto.

Para detalhar e ilustrar clinicamente a importância da percepção sensória e da memória implícita na etiologia do SP, o autor vale-se dos sintomas da enurese, da sudorese e da salivação intensa.

A enurese noturna é freqüente na clínica e é objeto de extensa pesquisa na pediatria, na psiquiatria e na psicanálise. É uma manifestação psicossomática de etiologia desconhecida e de tratamento não-específico. Traz para a criança e para aqueles que a cuidam incômodos e embaraços que, invariavelmente, conduzem a dificuldades no relacionamento familiar e social, muitas vezes sob forma de traumas físicos e psíquicos, com seqüelas irreversíveis na vida adulta. Seu portador fica indelevelmente marcado por traumas. Costuma ser interpretado psicanaliticamente, como representante simbólico de uma excitação erótica reprimida ou de ódio reprimido voltado para a mãe ou substituto, impedido de ser verbalizado.

A sudorese intensa, também, é ligada a um elemento líquido, no caso, o suor. Normalmente, é atribuída à ansiedade edípica (ansiedade de castração). Acontece em situações diversas, como viagens de avião, entrevista para admissão em emprego ou exposição em público.

A salivação, embora menos freqüente, costuma passar despercebida, embora muito incômoda para seu portador, podendo produzir alterações na dentição e na mucosa bucal.

O autor propõe a hipótese de que esses sintomas são representantes da defesa biológica instintiva da autogeração de percepções sensórias, utilizando, para tanto, a urina e o suor sobre a pele e a salivação sobre a mucosa bucal. Assemelham-se aos eczemas que obrigam seus portadores a se coçarem continuamente. São percepções que conferem ao agente a noção de estar existindo, de coesão física e psíquica, que pode ser testada por todos nós, quando prensamos uma caneta nas mãos ou nos dentes.

$\mathrm{O}$ autor intui que, no início, logo após a fecundação, as percepções sensórias do feto são aquelas ligadas aos processos vitais de anabolismo e 
catabolismo celular, assim como aos batimentos cardíacos, movimentos intestinais e funções respiratórias da mãe, que têm o mesmo ritmo e intensidade.

Mais tarde, com a maturação biológica do feto, este se torna capaz de autogerar percepções sensórias com o auxílio de elementos corporais seus, com as superfícies sensórias do próprio corpo.

Tustin $^{10}$ descreveu a importância dessas percepções produzidas pelo bebê ou pelo recémnascido utilizando-se de elementos macios e duros do seu próprio corpo sobre suas superfícies sensórias, principalmente a pele. Entre os primeiros, estão a saliva, a urina, os vômitos, as fezes liquefeitas, o muco das vias aéreas e depois o suor e a lágrima, que denominou de "formas autistas". Entre os segundos, estão as fezes, a língua, os dedos, as mãos, os pés e os punhos, que denominou de "objetos autistas". A ultrasonografia fetal mostra de forma bastante evidente o feto com as mãos, os dedos e a língua na boca, assim como movimentos de tocar com as mãos e os dedos seu órgão genital, os lóbulos das orelhas e outras partes do corpo. Se estivermos atentos, podemos observar que são movimentos executados com o mesmo ritmo e intensidade. Têm a mesma regularidade dos movimentos autonômicos vitais do feto e da mãe. Essas ações reflexas de autogeração de percepções sensórias persistem na vida pós-natal até a senilidade. Aparecem sob a forma de morder ou tocar os lábios e a boca com a língua, dedos e outros objetos duros ou macios. Também o salivar, o roer as unhas, o apertar objetos duros com a mão, o balanceio cadenciado do corpo e das pernas. Outros representantes na vida adulta são os toques repetidos das contas de um terço com os dedos, os banhos demorados, o enrolar os cabelos da cabeça com os dedos e outros tantos. É costume universal do povo islâmico o uso do masbarah, um cordão de contas de material duro, ajeitadas de forma semelhante às contas de um terço dos católicos. Seus usuários ficam tocando as contas com as pontas dos dedos da mão para se serenarem por longo tempo no dia. Esses arranjos acompanham o indivíduo pela vida toda e foram denominados de "barreiras autistas" por Tustin. Irão constituir a personalidade autista, se sua presença é muito evidente.

Esses objetos e formas autistas são anteriores aos “objetos transicionais" de Winnicott ${ }^{19}$. Segundo ele: "É sabido que os bebês, assim que nascem, tendem a usar o punho, os dedos e os polegares em estimulação da zona erógena oral, para satisfação dessa zona, e em tranqüila união. É igualmente sabido que, após alguns meses, bebês de ambos os sexos passam a gostar de brincar com bonecas e que a maioria das mães permite aos seus bebês algum objeto especial, esperando que eles se tornem, por assim dizer, apegados a tais objetos". Embora possa existir esse componente sexual, Winnicott não relacionou essas experiências com a percepção sensória em busca de apaziguamento para uma angústia de morte. Mantevese preso à teoria freudiana da pulsão libidinosa.

Tustin ${ }^{10}$ também não se desvencilhou por completo dessa teoria clássica da satisfação das zonas eróticas, mas considerou essas ações como movimentos em busca de coesão e tranqüilidade ao seu portador.

Freud $^{8}$ relacionou esse estado ao "princípio de conservação", e apontou para uma psicopatologia anterior à da repressão sexual, ligada à morte, mas não deu prosseguimento a esse estudo.

\section{$O$ retraimento autista}

O termo "autista" tem a ver com o primeiro estado biológico do ser emergente. Este é organizado sob a égide da homeostase com todas as condições ótimas para a continuidade dos processos de maturação biológica e sua manutenção. Nesse estado, há uma absorção e consumo de oxigênio pela célula em quantidades mínimas, suficiente para fornecer a energia necessária aos processos vitais, como mostram experiências recentes de Eric et al. ${ }^{20}$ Denominaram-nas de "suspensão animada" devido ao estado próximo da inércia vegetativa. Essas experiências têm demonstrado que, através de isquemia produzida, pode-se prolongar a vida de órgãos para transplante por técnicas que reduzem o consumo de oxigênio pelo órgão a ser transplantado.

É proposto, neste trabalho, que qualquer trauma com noção da descontinuidade do existir promove, mesmo no período fetal, de forma instintiva, um retorno do seu portador ao estado homeostático anterior para prolongar a vida. $\mathrm{O}$ autor denomina esse retorno de retraimento autista e o considera elemento importante na etiologia do SP.

\section{A teoria do trauma segundo o DSM-IV}

O trauma é definido pelo DSM-IV ${ }^{21}$ como "um acontecimento que determina em sua vítima ou testemunha uma noção concreta de morte". Tem desdobramentos orgânicos e psíquicos importantes, que vão desde a imobilidade até a hiperatividade física e psíquica, já descrita pelo autor ${ }^{22}$.

O trauma fetal pode ser resultante do traumatismo de parto, de estados tóxicos e infecciosos durante a gravidez, de malformação congênita e qualquer fator que coloca a sobrevivência do feto ou recém-nascido em risco. 
Como dito, ocorre um retraimento autista com presença de imobilismo, sem conseqüências patológicas, se transitório, como acontece no trabalho de parto normal ou uma situação existencial passageira. É regido pelo sistema nervoso parassimpático.

Pode ocorrer uma outra resposta caracterizada pela hiperatividade, e suas funções vitais são ordenadas pelo sistema nervoso simpático. Se prolongada, dá início a um processo de desgaste, que Selye ${ }^{23}$ denominou de estresse. Desencadeia a denominada "síndrome de adaptação geral”, que envolve a hipófise, o hipotálamo, o sistema nervoso simpático e parassimpático e a as glândulas supra-renais. Termina com uma alteração morfológica irreversível do órgão e um estado de insuficiência orgânica e psíquica, como se observa no paciente psicossomático. Geralmente, está insuficiente para a vida familiar, social, sexual e profissional.

Tanto a hipo como a hiperatividade dependem da avaliação intuitiva do nosso cérebro reptilíneo da gravidade, da intensidade, da iminência do perigo e das experiências traumáticas anteriores para optar pelos movimentos de imobilismo, de luta, ou de fuga. O corpo chega antes da cognição.

Scaer $^{24}$ fez a importante consideração de que o efeito patológico do trauma sobre sua vítima depende da predisposição desta. Verificou que acidentes automobilísticos graves nem sempre produziam efeitos de transtorno de estresse pós-traumático, enquanto outros insignificantes o produziam. O autor propõe que essa predisposição é condicionada pela personalidade autista, resultante da fixação da vítima no estado autista, ao qual retorna como se já soubesse o caminho.

\section{Caso clínico}

L. estava com 34 anos quando iniciou a psicoterapia psicanalítica com o autor, com duas sessões semanais. Queixava-se de bruxismo acentuado, eczema grave, constipação intestinal acentuada, incapacidade para o trabalho e desinteresse pela vida. Desde a adolescência apresentava ocasionalmente esses sintomas, que se agravaram aos 27 anos, após a morte do tio com quem trabalhava.

Informa que o pai faleceu quando nova, e a mãe foi obrigada a trabalhar. Passou a cuidar, em casa, dos irmãos menores. Na juventude, teve dificuldades escolares de relacionamento com colegas pelo seu temperamento de pessoa isolada e calada. Apresentou amenorréia prolongada. Aos 18 anos, começou a trabalhar na empresa do tio, que lhe demonstrou afeto e confiança. Dedicou-se ao trabalho e foi assumindo sua direção. Conseguiu formar um pequeno patrimônio.

Casou-se com 22 anos, mas separou-se 1 ano depois, pela intolerância ao modo extrovertido do marido, que colidia com alguns rituais comedidos de alimentação e de diversão e com seu apego à família e ao trabalho. Aos 27 anos, seu tio morreu, e a família deste a impediu de continuar na empresa.

O bruxismo obrigou-a a longo tratamento odontológico para não perder os dentes. Fez vários tratamentos médicos desde então, durante todos os anos seguintes, sem melhoras.

Aos 32 anos, foi convidada pelos familiares que a afastaram da empresa para retomar sua direção. Sentiuse física e psiquicamente insuficiente. Optou por trabalhos artesanais de bordado, que exercia com habilidade e lhe rendiam algum dinheiro. Nessa época, procurou tratamento com o autor.

Após 2 anos, apresentou melhoras apreciáveis. Entendeu a importância da reincidência traumática das perdas do pai e do tio para o agravamento de seus sintomas e que estes resultavam da sua necessidade de produzir percepções sensórias para se sentir com vida. Estava se refazendo com o auxílio da manutenção regular do setting, através dos horários regulares, pelo tratamento afetivo constante do autor, por meio do olhar, da fala e da compreensão empática.

Também estava sendo útil o trabalho interpretativo da sua relação com a insuficiência para o viver. Subestimava-se e era subestimada pelos outros, fato que a mantinha em constante baixa estima. Continua em tratamento.

\section{Conclusão}

Pelo exposto, a etiologia do SP está relacionada à reincidência traumática em paciente portador de personalidade autista. O corpo se converte, pela presença da homeostase, na "mãe suficientemente boa", conceito desenvolvido por Winnicott"

Um setting terapêutico adequado, fornecido principalmente pela constância da confiança no psicoterapeuta, mantém semelhanças com a homeostase, e o paciente poderá retomar seus processos de maturação. O mecanismo de cura é lento e passa pela afetividade, segundo Almeida ${ }^{25} \mathrm{O}$ trabalho interpretativo fica destinado aos elementos da transferência/contratransferência e da relação do paciente com sua doença, elementos estes relacionados à matriz psíquica esquizoparanóide, depressiva e edipiana.

Pode-se fazer a conjetura de que a questão da "fragilidade dos órgãos" remontaria ao momento do trauma com a embriologia de determinado órgão. Esse trauma seria registrado pela memória de procedimento e evocado posteriormente diante de novo trauma, recaindo o peso biológico sobre o órgão afetado anteriormente. 
Há necessidade de mais estudos conduzidos de forma articulada entre psicanalistas, psiquiatras e neurocientistas.

\section{Referências}

1. Sigmund F. Uma nota sobre o inconsciente na Psicanálise. Rio de Janeiro: Imago; 1969.

2. Ferenczi S. Further contributions to the theory and technique of Psycho-analysis. London: Hogarth; 1926.

3. Cannon WB. The wisdom of the body. New York: WW Norton; 1939.

4. Alexander F. El enfoque psicosomático en medicina. Buenos Aires: Paidos; 1962.

5. Dunbar HF. Mind and body: psychosomatic medicine. New York: Random; 1947.

6. Kandel E. A biologia e o futuro da psicanálise: um novo referencial intelectual para a psiquiatria revisitado. Rev Psiquiatr RS. 2003;25(1):139-65.

7. Sigmund F. Projeto para uma psicologia científica. Rio de Janeiro: Imago; 1969.

8. Sigmund F. Além do principio do prazer. Rio de Janeiro: Imago; 1969.

9. Winnicott DW. Textos selecionados: da pediatria à psicanálise. Rio de Janeiro: Francisco Alves; 1978.
10. Tustin F. Barreiras autistas em pacientes psiconeuróticos. Porto Alegre: Artmed; 1990

11. McDougall J. Theaters of the body. New York: WW Norton; 1989.

12. Marty P, M'Uzan M. O pensamento operatório. Rev Bras Psicanal. 1994;28(1):165-74.

13. Winnicott DW. A natureza humana. Rio de Janeiro: Imago; 1988.

14. Salim AS. O autismo psicogênico, a personalidade autista e o trauma. Rev Soc Psicanal RJ. 2006;XX:119-38.

15. Ogden T. Sobre o conceito de uma posição autística-contígua. Rev Bras Psican. 1989;30(2):341-64.

16. Sigmund F. O ego e o Id. Rio de Janeiro: Imago; 1969

17. Harlow H. The nature of love. Am Psychol. 1958;13:673-85.

18. Levine S. Infantile experience and resistance to physiological stress. Science. 1962;135:405-6.

19. Winnicott DW. O brincar e a realidade. Rio de Janeiro: Imago; 1975.

20. Blackstone E, Morrison M, Roth MB. H2S induces a suspended animation-like state in mice. Science 2005;308(5721):518.

21. American Psychiatric Association. DSM-IV - Diagnostic and statistical manual of mental disorders. 4th ed. Washington: Am Psychiatr Assoc; 1994.

22. Salim AS. Remendos para uma superfície sensorial. Rev Soc Bras Psicanal Porto Alegre. 2002;4:437-50.

23. Selye H. The general adaptation syndrome and the diseases of adaptation. J Clin Endocrinol. 1946;6:117-25.

24. Scaer CR. The body bears the burden. New York: Haworth; 2001.

25. Andrade VM. Affect and the therapeutic action of psychoanalysis. Int J Psychoanal. 2005;86(Pt 3):677-97. 